\title{
As needed in line suction catheter changes were as safe as and less expensive than daily scheduled catheter changes during mechanical ventilation
}

\author{
Kollef MH, Prentice D, Shapiro SD, et al. Mechanical ventilation with or without daily changes of in-line suction catheters. Am J \\ Respir Crit Care Med 1997 Aug;156:466-72.
}

\section{Question}

How safe are, and what are the costs of, daily scheduled changes ( $v$ as needed changes) on in line suction catheters for patients who receive mechanical ventilation?

Design

Randomised controlled trial.

\section{Setting}

A university teaching hospital in St Louis, Missouri, USA.

\section{Patients}

521 patients (mean age 58 y, $54 \%$ men, $66 \%$ white) who were $>18$ years old and required mechanical ventilation for $>12$ hours while in the intensive care unit (ICU). Exclusion criteria were mechanical ventilation in another hospital, heart or lung transplantation, or massive haemoptysis.

\section{Intervention}

263 patients were allocated to receive changes of in line suction catheters every 24 hours. 258 patients were allocated to receive non-scheduled changes of suction catheters indicated by mechanical failure of the device or visible soiling of the catheter. Routine nursing and respiratory treatment suctioning practices were done for all patients. Standard commercial equipment was used and metred dose inhalers and attached chamber devices were used to deliver medication dispersed in an aerosol.

\section{Main outcome measures}

The main outcome was ventilator associated pneumonia (VAP). Secondary outcomes were duration of mechanical ventilation, length of ICU and hospital stay, number of acquired organ system derangements (Organ System Failure Index), hospital mortality, mortality associated with VAP, and total costs for catheter changes.

\begin{abstract}
Main results
Patients who received scheduled changes had a mean of 4.7 changes compared with 0.4 changes per person in the as needed group $(\mathrm{p}<0.001)$. The groups did not differ for any other outcome including VAP (14.7\% for as needed changes $v 14.8 \%$ for scheduled changes, $\mathrm{p}=0.97$ ), episodes of VAP/1000 ventilator days $(25.8 v 27.5, \mathrm{p}=0.8)$, VAP in patients who needed mechanical ventilation for $>7$ days $(50 \% v 63 \%, \mathrm{p}=0.2)$, duration of mechanical ventilation $(5.7 v 5.4 \mathrm{~d}, \mathrm{p}=0.7)$, length of ICU stay (6.9 $v 7.0 \mathrm{~d}, \mathrm{p}=0.9)$, length of hospital stay (14.4 $v 14.7$ $\mathrm{d}, \mathrm{p}=0.8)$, acquired organ system derangements (1.2 $v 1.1$, $\mathrm{p}=0.3)$, hospital mortality $(26 \% v 24.3 \%, \mathrm{p}=0.7)$ and mortality attributed to VAP $(1.9 \%$ v $1.5 \%, \mathrm{p}=0.7)$. Total costs were $\$$ US11 016 for the scheduled group and $\$ 837$ for the as needed group. Characteristics that predicted VAP were being a man $(p=0.02)$, black race $(p=0.02)$, low premorbid lifestyle score $(p=0.02)$, high Acute Physiology and Chronic Health Evaluation II (APACHE) score $(\mathrm{p}=0.01)$, low $\mathrm{P}_{\mathrm{a}} \mathrm{O}_{2} / \mathrm{FIO}_{2}(\mathrm{p}=0.009)$, previous intubation during same hospital stay $(\mathrm{p}<0.001)$, receipt of sucralfate $(\mathrm{p}=0.004)$, receipt of medication dispersed in an aerosol $(\mathrm{p}<0.001)$, receipt of previous antibiotic treatment $(\mathrm{p}=0.03)$, and having had a tracheostomy $(\mathrm{p}<0.001)$.
\end{abstract}

\section{Conclusion}

As needed in line suction catheter changes during mechanical ventilation were as safe as scheduled daily changes for ventilator associated pneumonia and costs were much less.

\section{Source of funding: BJC Innovations in Healthcare Program.}

For article reprint:Dr M H Kollef, Pulmonary and Critical Care Division, Washington University School of Medicine, Box 8052, 660 South Euclid Avenue, St Louis, MO 63110, USA. Fax +1314 3621334.

\section{Commentary}

Endotracheal suctioning is an important supportive treatment for patients requiring mechanical ventilation. Traditionally, in line suction catheters are changed every 24 hours to prevent the development of VAP. A paucity of research exists on the use of in line suction catheters and the optimal time for change. The study by Kollef $e t a l$ is one of very few that attempts to evaluate a closed multiple use suction catheter system for outcomes of safety and cost.

The study was limited to 1 North American hospital. Results may have differed if other populations had been included in the study.

Strengths of the study included the random allocation of eligible patients to groups and the attempt to keep caregivers blinded by doing scheduled in line suction changes during evening or night shifts. The diagnosis of VAP was acknowledged as a potential limitation of the study because it was based on clinical criteria and did not include quantitative cultures of lower respiratory tract secretions which would have provided more objective information. ${ }^{1}$ No reference was made to a nationally agreed definition of VAP which would have been useful, however reference is made to evidence which suggests that invasive diagnostic testing is unnecessary. ${ }^{2}$ Hence, the means of diagnosis appear reasonable, but open to debate. The method of humidification was an important variable which could have influenced the outcome of VAP. Efficacy of different methods was not discussed nor were reasons given for the choices that were made. Joynt and Lipman describe heat moisture exchange filters that provide adequate humidification with a possible reduced risk of nosocomial pneumonia. ${ }^{3}$ Perhaps more emphasis could have been placed on the criteria for choice.
This study has important implications for nursing practice in the ICU. Changing in line suction catheters as needed minimises the number of manipulations of the ventilator circuitry, reducing the risk of cross contamination and the risk of VAP. The importance of effective hand hygiene and the use of protective clothing such as gloves and aprons cannot be overemphasised.

\section{Kathryn Little, RGN, BSc, PGCE} Lecturer, School of Nursing University of Hull Willerby, $U K$

1 Stott S, Webster N. Nosocomial pneumonia. Care of the Critically Ill 1997;13:139-44.

2 Niederman M, Torres A, Summer W. Invasive diagnostic testing is not needed routinely to manage suspected ventilator associated pneumonia. Am J Respir Crit Care Med 1994;150: monia.

3 Joynt G, Lipman J. The use of heat moisture exchangers in critically ill patients. Care of the Critically Ill 1994;10:271-5. 